07.79.-v - 39.30. $+\mathrm{w}-68.45 .-\mathrm{v}-81.70 .-\mathrm{q}-82.65 .-\mathrm{i}$

\title{
Theoretical and Practical Aspects of Nuclear Microprobe Analysis of Solid Surfaces and Bulk Solids
}

\author{
Patrick M. Trocellier \\ CEA-CNRS, Laboratoire Pierre Süe, Centre d’Études de Saclay, 91191 Gif sur Yvette Cedex, France
}

(Received September 28; accepted December 16, 1996)

\begin{abstract}
The aim of this paper is first to describe the nuclear microprobe and to present the analytical capabilities of the different methods involved in nuclear microanalysis resulting from the interactions between the incident ion beam and the solid target, such as proton induced X-ray emission, proton induced gamma-ray emission, Rutherford backscattering spectrometry, non-Rutherford scattering, elastic recoil detection and nuclear reaction spectrometry. The respective analytical performances are also discussed. The second purpose of this paper is to illustrate some aspects of nuclear microanalysis applications from materials sciences to earth sciences and life sciences, using recently published data. Thirdly, both recent developments and further progresses in nuclear microprobe technology are detailed regarding as well ion sources, beam focussing as associated microscopic techniques, detection devices and data processing.
\end{abstract}

\section{Introduction}

It is now possible to easily obtain electron, ion, X-ray and laser microbeams. Over the past ten years, microanalysis has become a common tool for materials study and characterization in a huge number of research and industrial laboratories around the world. Progress is still running and nanoanalysis will become a common expression within the next ten years. Surface and bulk solid investigations are always based on the following dual principle: excitation of the target atoms by the primary probe and occurrence of secondary radiations - detection and processing of the analytical signals.

This paper deals with nuclear microanalysis in which a microbeam of $\mathrm{MeV}$ light ions such as protons, deuterons or helium-ions, is focussed on a target surface, producing atomic and nuclear interactions and leading to the emission of electromagnetic radiations and charged particles in the energy range $\mathrm{keV}-\mathrm{MeV}$. 


\section{Nuclear Microprobe}

2.1 Historical BACKGRound. - The first nuclear microprobe was built in 1972, in the Nuclear Physics Division of the Harwell Research Centre (U.K.). John Cookson and his group obtained a $3 \mathrm{MeV}$ proton microbeam with a diameter of about $4 \mu \mathrm{m}$. They showed that it is possible to reconstitute 2D images of a microscopy copper grid by scanning the beam on the sample and detecting simultaneously the induced X-ray and backscattered proton signals [1].

Presently, more than sixty nuclear microprobe facilities are in operation all over the world. The Fifth International Conference on Nuclear Microprobe Technology and Applications (ICNMTA'96) was recently held in Santa Fe, New Mexico (10-15 November 1996).

2.2 DeSCRIPTION. - In a nuclear microprobe, the ion source is constituted by an electrostatic particle accelerator (single ended Van de Graaff or Tandem) or by a cyclotron. After transmission through object slits, the ion beam is focussed down to a few micrometer square using electromagnetic quadrupoles [2]. The microbeam hits a target placed in a vacuum chamber equipped with an optical microscope, scanning plates and various detection devices [3].

The nuclear microprobe facility of the Pierre Süe Laboratory is schematically displayed in Figure 1. Interactions between the incident ions and the target atoms generate secondary electrons, $\mathrm{X}$-rays, scattered particles, gamma-rays and nuclear reaction products which are detected using appropriate energy-dispersive solid detectors: Si-Li detector for X-rays, hyper pure Ge detector for gamma-rays and silicon surface barrier detectors for charged particles (Fig. 2). Thus, several analytical methods, which are described in the next section, can be performed simultaneously from proton induced X-ray emission (PIXE) or proton induced gamma-ray emission (PIGE) to Rutherford backscattering spectrometry (RBS), proton or helium enhanced scattering analysis (PHESA), elastic recoil detection analysis (ERDA) and nuclear reaction analysis (NRA). A recent review written by Revel and Duraud contains an abundant bibliography on this subject [4].

2.3 Analytical Methods: Basic Principle and Performances. - Table I summarizes the main characteristics of the six ion beam analytical methods listed above.

2.3.1 Proton Induced X-ray Emission. - As in the case of Electron Induced X-ray Emission currently used with an electron probe, PIXE is based on the detection of the $1 \mathrm{keV}-30 \mathrm{keV}$ X-rays generated by the excitations and ionizations of the target atoms by the $\mathrm{MeV}$ incident protons. Due to the low bremsstrahlung background produced by protons compared with that created by electrons $(1 / m$ dependence of the bremsstrahlung yield), PIXE is not only suited for major and minor elements but also for trace element analysis in solids from $Z=11$ to $Z=92$. Detection limits are strongly dependent on the incident energy (X-ray emission cross section) and on target composition as it is shown in Figure 3 from Johansson and Campbell [5], detection limits as low as a few weight ppm can be obtained.

For a thin target, the X-ray yield is expressed by the following equation:

$$
I_{\mathrm{X}}^{j}=N_{\mathrm{i}} n_{0} t \sigma_{E_{\mathrm{i}}} \omega_{\mathrm{X}} k_{\mathrm{X}}^{j} \varepsilon \Delta \Omega
$$

with $n_{0}$ the volumic density of target atoms $\left(\mathrm{cm}^{-3}\right), t$ the film thickness $(\mathrm{cm}), N_{\mathrm{i}}$ the incident ion fluence $\left(\mathrm{cm}^{-2} \mathrm{~s}^{-1}\right), \sigma_{E_{\mathrm{i}}}$ the ionization cross-section at energy $E_{\mathrm{i}}\left(\mathrm{cm}^{2}\right), \omega_{\mathrm{X}}$ the fluorescence yield, $k_{\mathrm{X}}^{j}$ the relative intensity of the X-ray line $j, \varepsilon$ the detector efficiency and $\Delta \Omega$ the detector solid angle.

For a thick target, this equation has to be integrated over the whole range of the incident ion within the target using a term: $\sigma(E) T^{j}(E) / S(E)$ where $S(E)$ represents the stopping power of 


\section{NUCLEAR MUCROPROBE}

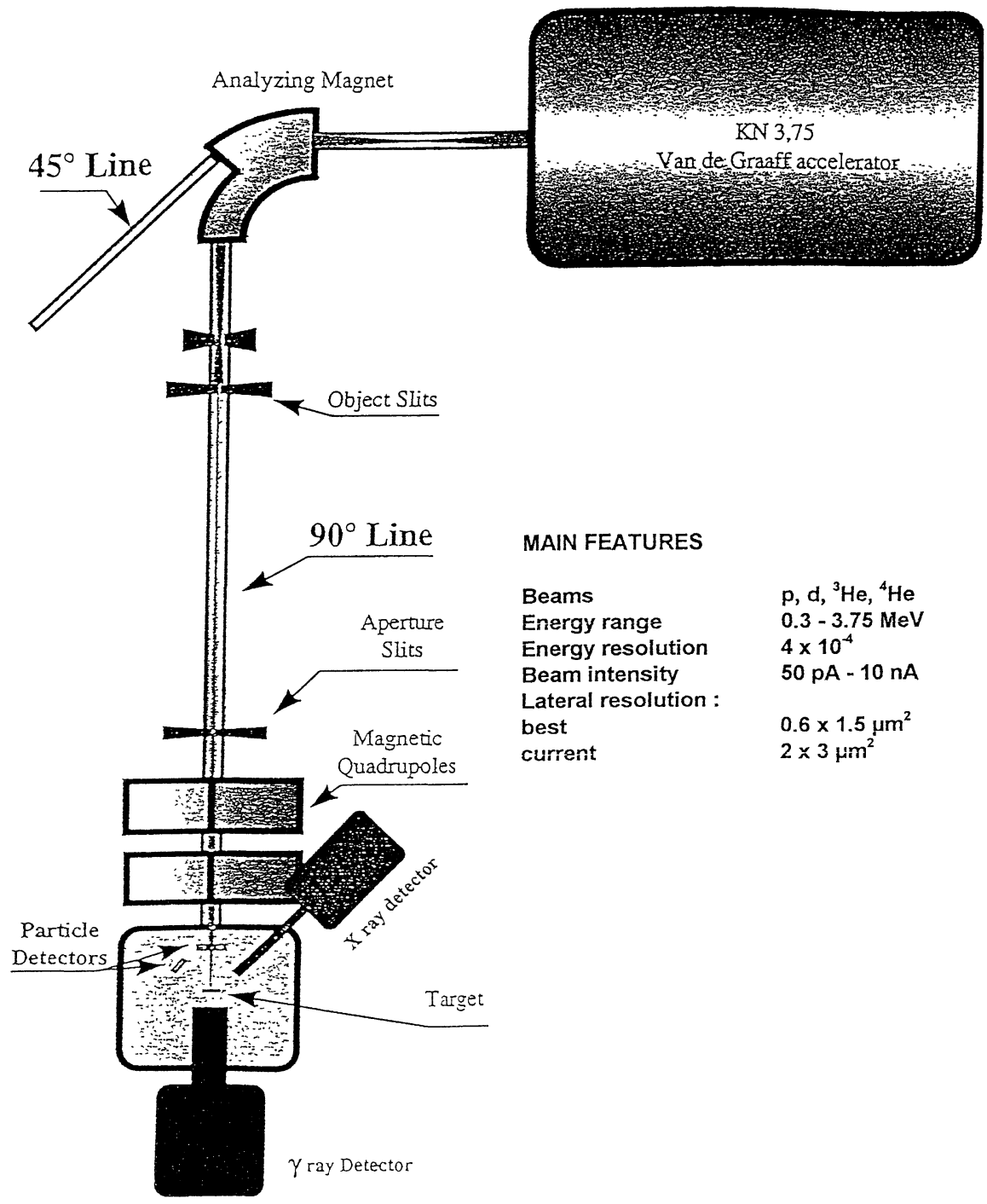

Fig. 1. - General layout of a nuclear microprobe (the Laboratoire Pierre Süe nuclear microprobe facility).

the target medium for energy $E$ and $T^{j}(E)$ is the transmission factor of the X-ray line $j$ exponentially depending on the mass attenuation factor $(\mu / \rho)^{j}$. X-ray emission can also be performed using deuterons or helium ions as projectiles [5].

2.3.2 Proton Induced Gamma-Ray Emission. - Proton induced gamma-ray emission looks like PIXE but it concerns the excitation of the nuclei of target atoms. Table II lists the main nuclear reactions leading to the emission of characteristic gamma-rays used for elemental analysis. Each nuclear reaction is labelled as $\mathrm{A}(\mathrm{a}, \mathrm{b}) \mathrm{B}$ with $\mathrm{A}$ the target nucleus, a the incident ion, $\mathrm{B}$ the residual nucleus and $\mathrm{b}$ the reaction product. Three possibilities exist for $\mathrm{b}: \gamma, \alpha \gamma$, or $\mathrm{p}^{\prime} \gamma$. In terms of 


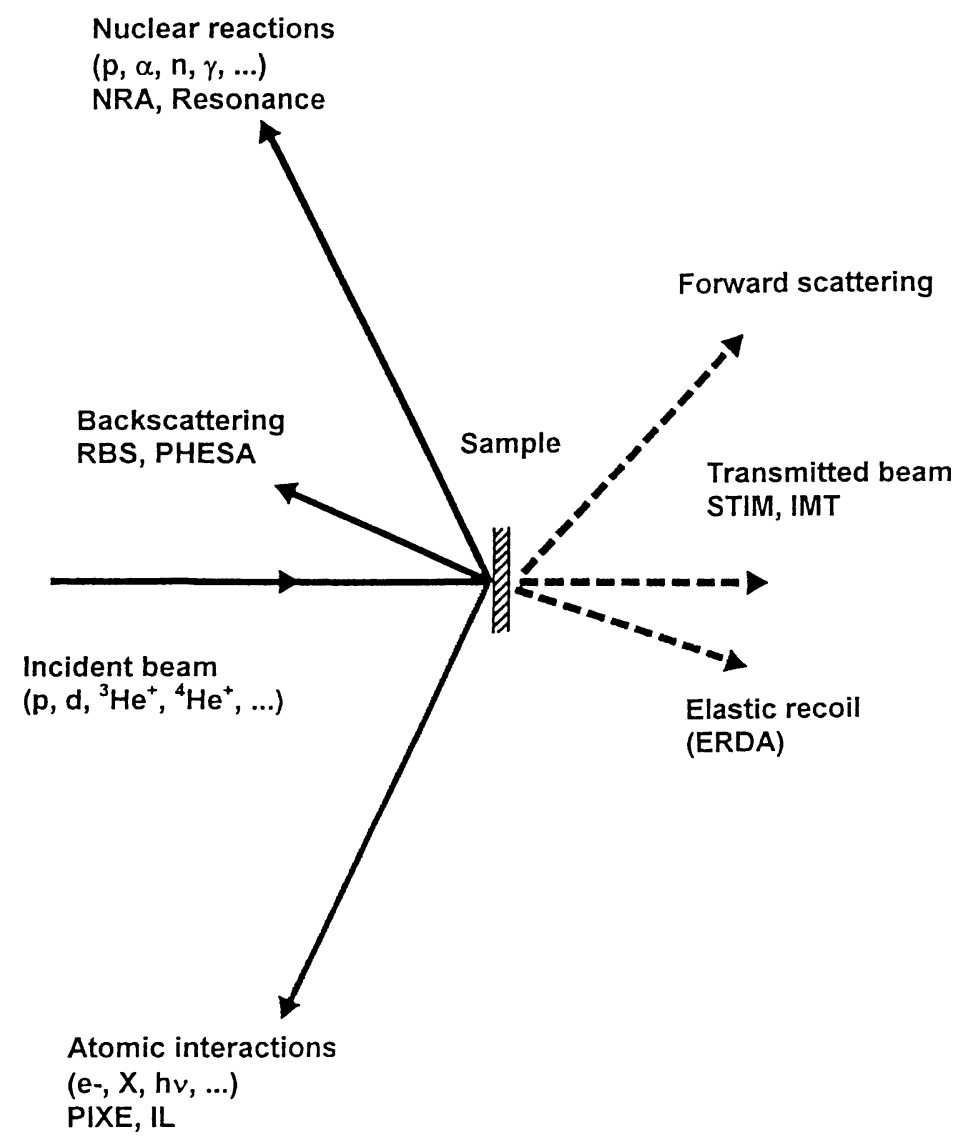

Fig. 2. - Description of the interactions between an incident ion beam and target atoms in the MeV energy range.

nuclear interactions, the first one corresponds to radiative capture, the second to nuclear reaction and the third one to inelastic diffusion. Typical gamma-ray energy ranges from $100 \mathrm{keV}$ to $5 \mathrm{MeV}$, and exceptionally rises up to $10-20 \mathrm{MeV}$. One of the most difficult problem to solve with PIGE is to avoid energy interferences in gamma-ray energies. Practically, PIGE permits to determine the isotopes of light and medium elements from $Z=3$ to $Z=17$ in bulk solids with detection limits lower than $0.1 \mathrm{wt} . \%$ [6].

The gamma-ray yield is derived from an equation analog to equation (1) assuming that the attenuation process can be neglected in first approximation:

$$
I_{\mathrm{g}}^{j}=N_{\mathrm{i}} n_{0} k_{\mathrm{g}}^{j}\left[\int_{E_{\mathrm{i}}}^{0} \sigma(E) / S(E) \mathrm{d} E\right] \varepsilon \Delta \Omega .
$$

Gamma-ray emissions induced by deuterons (DIGE) or by helium-4 ions (AIGE) have also been largely developed [7].

2.3.3 Rutherford Backscattering Spectrometry. - Elastic collisions between incident ions and target nuclei are the basis of three scattering methods: RBS when the collision is purely Coulombian, 
Table I. - Characteristics of the main ion beam analytical techniques.

\begin{tabular}{|c|c|c|c|}
\hline Method & In & Out & Application field \\
\hline $\begin{array}{l}\text { Proton Induced } \\
\text { X-ray Emission } \\
\text { (PIXE) }\end{array}$ & $\mathrm{p}(1-4 \mathrm{MeV})$ & $\begin{array}{c}\text { X-rays } \\
1-35 \mathrm{keV}\end{array}$ & $\begin{array}{l}\text { * Detection of trace } \\
\text { elements }(\mathrm{Na} \text { to } \mathrm{U})\end{array}$ \\
\hline $\begin{array}{l}\text { Proton Induced } \\
\text { Gamma-ray } \\
\text { Emission (PIGE) }\end{array}$ & $p(1-4 \mathrm{MeV})$ & $\begin{array}{l}\text { gamma-rays } \\
0.1-20 \mathrm{MeV}\end{array}$ & $\begin{array}{l}\text { * Analysis of major and } \\
\text { minor elements ( } \mathrm{Li} \text { to } \mathrm{Ga}) \\
{ }^{*} \text { Isotopic ratio }(\mathrm{Li}, \mathrm{B}, \mathrm{Mg})\end{array}$ \\
\hline $\begin{array}{c}\text { Rutherford } \\
\text { Backscattering } \\
\text { Spectrometry (RBS) }\end{array}$ & ${ }^{4} \mathrm{He}^{+}(1-4 \mathrm{MeV})$ & scattered ions & $\begin{array}{c}\text { * Thin film analysis } \\
\text { * Distribution of heavy } \\
\text { elements in light samples }\end{array}$ \\
\hline $\begin{array}{l}\text { Non-Rutherford } \\
\text { Scattering } \\
\text { (PHESA) }\end{array}$ & $\begin{array}{c}\mathrm{p}(1-4 \mathrm{MeV}) \\
{ }^{4} \mathrm{He}^{+}(3-8 \mathrm{MeV})\end{array}$ & scattered ions & $\begin{array}{l}\text { * Distribution of light } \\
\text { elements (Li to Si) }\end{array}$ \\
\hline $\begin{array}{l}\text { Elastic Recoil } \\
\text { Spectrometry } \\
\text { (ERDA) }\end{array}$ & ${ }^{4} \mathrm{He}^{+}(2-4 \mathrm{MeV})$ & recoil ions & ${ }^{*}$ Hydrogen profiling \\
\hline $\begin{array}{l}\text { Nuclear reaction } \\
\text { Analysis (NRA) }\end{array}$ & $\begin{array}{c}\mathrm{p}(0.1-4 \mathrm{MeV}) \\
\mathrm{d}(0.1-2.5 \mathrm{MeV}) \\
{ }^{3} \mathrm{He}^{+}(0.5-4 \mathrm{MeV}) \\
{ }^{4} \mathrm{He}^{+}(1-4 \mathrm{MeV})\end{array}$ & $\begin{array}{l}\text { charged } \\
\text { particles } \\
(p \text { or } \alpha)\end{array}$ & $\begin{array}{c}\text { Analysis of light element } \\
\text { isotopes ( } \mathrm{H} \text { to } \mathrm{S})\end{array}$ \\
\hline
\end{tabular}

PHESA when resonances appear in the scattering cross section and ERDA when collided atoms leaving the target are detected.

In the case of Rutherford backscattering, the energy of the $m_{0}$ ion scattered in the direction $\theta$ by a target atom $M_{\mathrm{i}}$ is derived from the incident ion energy by:

$$
\begin{gathered}
E_{\mathrm{i}}=K_{\mathrm{i}} E_{0} \\
K_{\mathrm{i}}=\left[M_{\mathrm{i}} \cos \theta+\left(M_{\mathrm{i}}^{2}-m_{0}^{2} \sin 2 \theta\right)^{1 / 2}\right]^{2} /\left(M_{\mathrm{i}}+m_{0}\right)^{2}
\end{gathered}
$$

with $K_{\mathrm{i}}$ the kinematic factor, $M_{\mathrm{i}}$ and $m_{0}$ the respective masses of the target atom and the incident ion (see also Fig. 4). The expression of the Rutherford cross-section is largely discussed in [8], it exhibits strong dependences with $Z_{\mathrm{i}}^{2}, 1 / \sin ^{4} \theta / 2$ and $1 / E_{0}^{2}$. Figure 4 also describes the elastic scattering process occuring in a solid target versus depth. The incident ion $\left(m_{0}, E_{0}\right)$ colliding with a surface target atom $\left(M_{\mathrm{i}}\right)$, is scattered in a direction $\theta$ with respect to its initial direction. The scattered ion carries an energy $E_{\mathrm{i}}=K_{\mathrm{i}} E_{0}$. Another incident ion penetrates into the sample to the depth $x$, looses part of his energy $\Delta E_{\text {in }}=\left(E_{0}-E_{0}^{\prime}\right)$, collides with a target atom $M_{\mathrm{i}}$ and is finally scattered in the same direction $\theta$ as the previous one. It starts with an energy $K_{\mathrm{i}} E_{0}^{\prime}$, looses part of its energy before reaching the target surface which it leaves with an energy $E_{\mathrm{f}}$ such as $\Delta E_{\text {out }}=E_{\mathrm{f}}-K_{\mathrm{i}} E_{0}^{\prime}$. Thus, the energy depth relationship can be easily deduced from the whole process:

$$
\Delta E / \Delta x=[S]=\left[K_{\mathrm{i}}(\mathrm{d} E / \mathrm{d} x)_{\text {in }}+(1 /|\cos \theta|)(\mathrm{d} E / \mathrm{d} x)_{\text {out }}\right] .
$$

The backscattering yield $Y_{\mathrm{i}}$ is in first approximation directly proportional to the concentration $N_{\mathrm{i}}$ of the target atom $M_{\mathrm{i}}$. For a thin target, the equation is:

$$
Y_{\mathrm{i}}=N_{\mathrm{i}} n_{0} \varepsilon \sigma\left(E_{0}, \theta\right) t \Delta \Omega \text {. }
$$



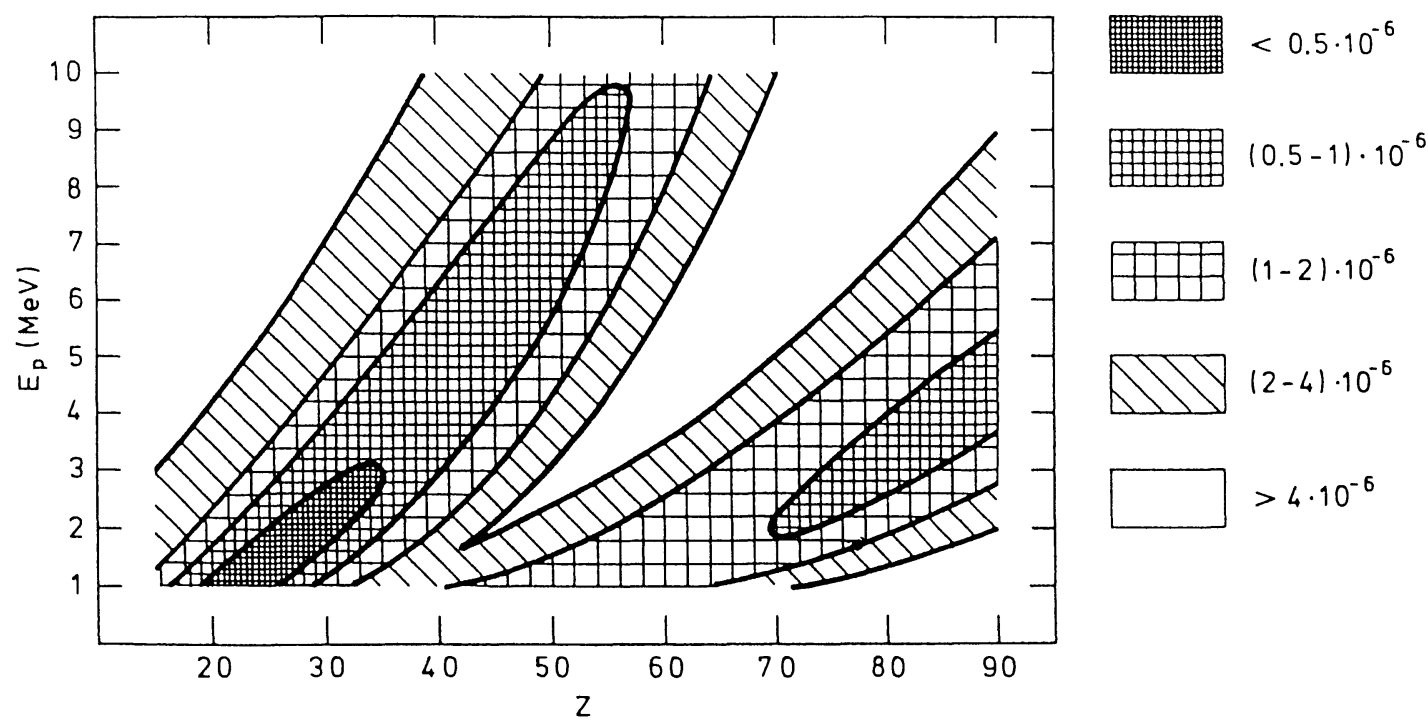

Fig. 3. - Variation of detection limit in terms of weight concentrations for PIXE analysis versus proton energy and atomic number of the target atom (from Johansson and Campbell [5]).

Table II. - Nuclear reactions leading to the emission of gamma-rays used for light element isotope analysis $[6,7,9]$.

\begin{tabular}{|c|c|c|}
\hline Isotope & Reaction & Gamma-rays \\
\hline${ }^{1} \mathrm{H}$ & ${ }^{1} \mathrm{H}\left({ }^{15} \mathrm{~N}, \alpha \gamma\right){ }^{12} \mathrm{C}$ & $4439 \mathrm{keV}$ \\
\hline${ }^{7} \mathrm{Li}$ & ${ }^{7} \mathrm{Li}\left(\mathrm{p}, \mathrm{p}^{\prime} \gamma\right){ }^{7} \mathrm{Li}$ & $478 \mathrm{keV}$ \\
\hline${ }^{10} \mathrm{~B}$ & ${ }^{10} \mathrm{~B}(\mathrm{p}, \alpha \gamma){ }^{7} \mathrm{Li}$ & $429 \mathrm{keV}$ \\
\hline${ }^{11} \mathrm{~B}\left(\mathrm{p}, \mathrm{p}^{\prime} \gamma\right){ }^{10} \mathrm{~B}$ & $718 \mathrm{keV}$ \\
\hline${ }^{12} \mathrm{C}$ & ${ }^{11} \mathrm{~B}\left(\mathrm{p}, \mathrm{p}^{\prime} \gamma\right){ }^{11} \mathrm{~B}$ & $2125 \mathrm{keV}$ \\
\hline${ }^{16} \mathrm{O}$ & ${ }^{12} \mathrm{C}\left(\mathrm{d}, \mathrm{p}^{13}{ }^{13} \mathrm{C}\right.$ & $3088 \mathrm{keV}$ \\
\hline${ }^{19} \mathrm{~F}$ & ${ }^{16} \mathrm{O}\left(\mathrm{d}, \mathrm{p}^{10}\right)^{17} \mathrm{O}$ & $871 \mathrm{keV}$ \\
\hline${ }^{23} \mathrm{Na}$ & ${ }^{19} \mathrm{~F}\left(\mathrm{p}, \mathrm{p}^{\prime} \gamma\right){ }^{19} \mathrm{~F}$ & $110 \mathrm{keV}$ \\
\hline${ }^{25} \mathrm{Mg}$ & ${ }^{23} \mathrm{Na}\left(\mathrm{p}, \mathrm{p}^{\prime} \gamma\right){ }^{23} \mathrm{Na}$ & $197 \mathrm{keV}$ \\
\hline${ }^{27} \mathrm{Al}$ & ${ }^{23} \mathrm{Na}(\mathrm{p}, \alpha \gamma){ }^{20} \mathrm{Ne}$ & $1639 \mathrm{keV}$ \\
\hline${ }^{28} \mathrm{Si}$ & ${ }^{25} \mathrm{Mg}\left(\mathrm{p}, \mathrm{p}^{\prime} \gamma\right){ }^{25} \mathrm{Mg}$ & $585 \mathrm{keV}$ \\
\hline${ }^{31} \mathrm{P}$ & ${ }^{27} \mathrm{Al}\left(\mathrm{p}, \mathrm{p}^{\prime} \gamma\right){ }^{27} \mathrm{Al}$ & $843 \mathrm{keV}$ \\
\hline${ }^{34} \mathrm{~S}$ & ${ }^{28} \mathrm{Si}\left(\mathrm{p}, \mathrm{p}^{\prime} \gamma\right){ }^{28} \mathrm{Si}$ & $1013 \mathrm{keV}$ \\
\hline${ }^{35} \mathrm{Cl}$ & ${ }^{31} \mathrm{P}\left(\mathrm{p}, \mathrm{p}^{\prime} \gamma\right){ }^{31} \mathrm{P}$ & $1779 \mathrm{keV}$ \\
\hline & ${ }^{34} \mathrm{~S}\left(\mathrm{p}, \mathrm{p}^{\prime} \gamma\right){ }^{34} \mathrm{~S}$ & $1266 \mathrm{keV}$ \\
\hline${ }^{35} \mathrm{Cl}\left(\mathrm{p}, \mathrm{p}^{\prime} \gamma\right){ }^{35} \mathrm{Cl}$ & $2127 \mathrm{keV}$ \\
\hline
\end{tabular}



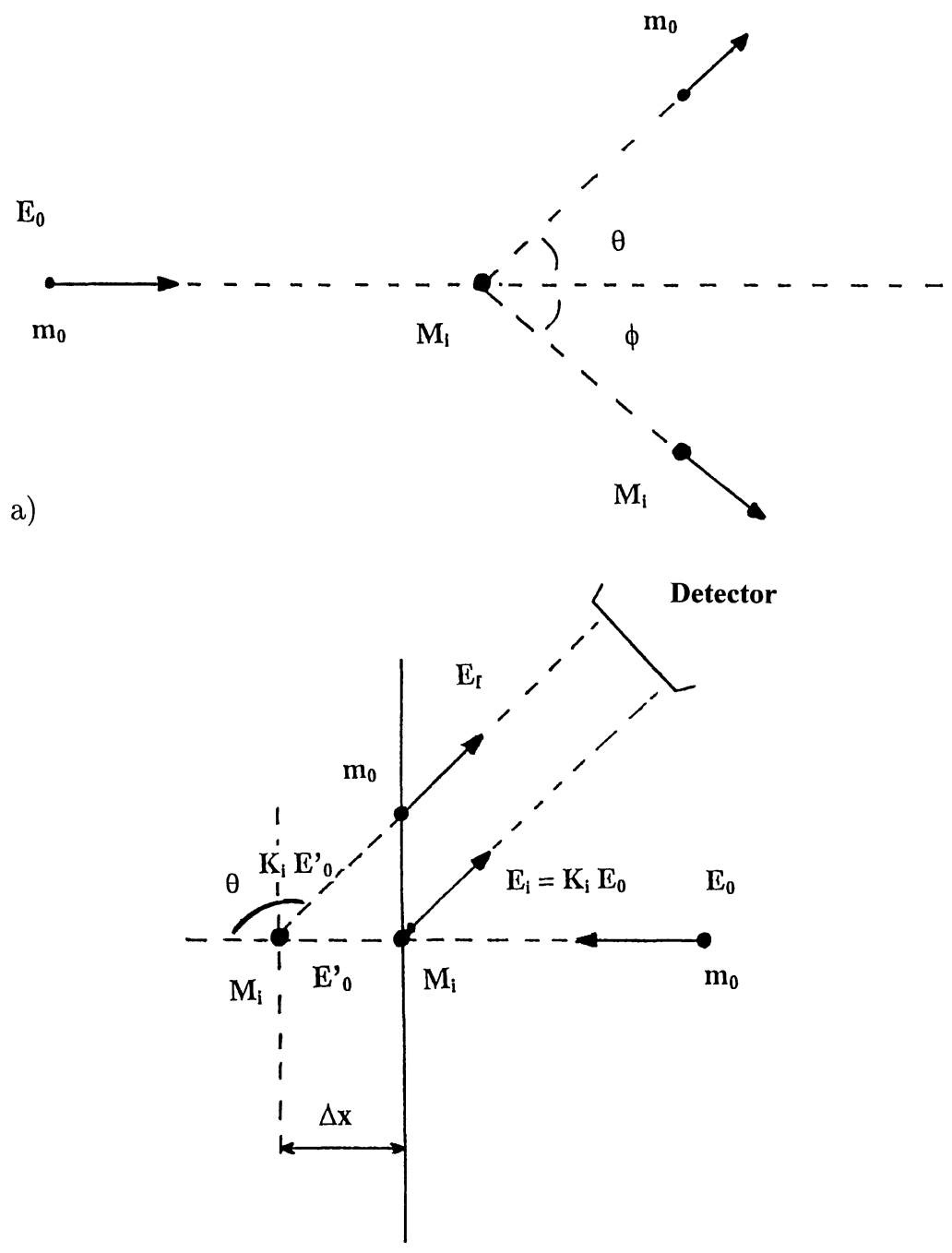

b)

Target surface

Fig. 4. - Description of both elastic scattering and recoil processes: a) elastic scattering $\left(m_{\mathrm{i}}, \theta\right)$ and elastic recoil $\left.\left(M_{\mathrm{i}}, \phi\right), \mathrm{b}\right)$ elastic scattering versus depth in a solid target.

For a thick target, equation (6) has to be integrated over the range of the incident ion, taking into account the energy loss effects described above.

Rutherford Backscattering Spectrometry is very convenient for thin film studies and for the determination of depth distribution of heavy impurities $\left(Z_{\mathrm{i}}>30\right)$ incorporated in a light substrate $\left(Z_{\mathrm{i}}<20\right)[8]$.

2.3.4 Non Rutherford Scattering or Resonant Scattering. - PHESA method is located at the frontier between RBS and Nuclear Reaction Analysis because it is based on the occurrence of nuclear resonances in elastic scattering. This phenomenon essentially concerns the nuclear structure of light elements from $\mathrm{He}$ to $\mathrm{Si}$. For discrete values of the incident ion energy, the relevant 
Table III. - Examples of resonant scattering interactions used in PHESA [6, 7, 9].

\begin{tabular}{|c|c|}
\hline Interaction & $\begin{array}{l}\text { Characteristics of the resonance } \\
\text { (energy, width, cross-section) }^{*}\end{array}$ \\
\hline${ }^{12} \mathrm{C}(\mathrm{p}, \mathrm{p}){ }^{12} \mathrm{C}$ & $\begin{array}{c}E=1.730 \mathrm{MeV}, \Gamma=40 \mathrm{keV} \\
\sigma=922 \mathrm{mb} / \mathrm{sr}\end{array}$ \\
\hline${ }^{16} \mathrm{O}(\mathrm{p}, \mathrm{p}){ }^{16} \mathrm{O}$ & $\begin{array}{c}E=3.480 \mathrm{MeV}, \Gamma=10 \mathrm{keV} \\
\sigma=230 \mathrm{mb} / \mathrm{sr}\end{array}$ \\
\hline${ }^{16} \mathrm{O}(\alpha, \alpha){ }^{16} \mathrm{O}$ & $\begin{array}{c}E=3.045 \mathrm{MeV}, \Gamma=10 \mathrm{keV} \\
\sigma=700 \mathrm{mb} / \mathrm{sr}\end{array}$ \\
\hline
\end{tabular}

${ }^{*}$ For a detection angle between 150 and $170^{\circ}$.

scattering cross-section drastically increases by 1 to 3 orders of magnitude in comparison with pure Coulombian scattering. Table III gives the main characteristics of proton or helium-4 induced resonant scattering used to determine light element distributions in the near surface region of medium mass solids $[6,9]$. PHESA has been recently applied for the characterization of light element thin films deposited on mineral substrates [10].

2.3.5 Recoil Spectrometry. - Elastic Recoil Detection Analysis is derived from elastic scattering spectrometry. It deals with the detection of the recoil nucleus after its collision with the incident ion (see Fig. 4) [11]. By analogy with equation (4), the energy of the recoil nucleus in the direction $\phi$ is:

$$
\begin{gathered}
E_{\mathrm{i}}^{\prime}=K_{\mathrm{i}}^{\prime} E_{0} \\
K_{\mathrm{i}}^{\prime}=4 M_{\mathrm{i}} m_{0} \cos ^{2} \phi /\left(M_{\mathrm{i}}+m_{0}\right)^{2} .
\end{gathered}
$$

The relationship between the scattering angle and the recoil angle is given by:

$$
\tan \theta=\sin 2 \phi /\left(m_{0} / M_{\mathrm{i}}\right)-\cos 2 \phi .
$$

A recently published book is exclusively devoted to elastic recoil spectrometry theory and applications [11], with a complete analysis of the experimental parameters involved, such as the recoil cross-section which does not obey the Rutherford model for the collision ${ }^{4} \mathrm{He}^{+} /{ }^{1} \mathrm{H}$. ERDA is currently applied for hydrogen profiling in solids using 2-4 MeV helium-4 ions with detection limits of the order of $50 \mathrm{wt} . \mathrm{ppm}$ [11].

2.3.6 Nuclear Reaction Analysis. - Nuclear Reaction Analysis is based on inelastic collisions between incident ions and target nuclei, leading to the formation of a reaction product together with a residual nucleus generally different from the initial one. Table IV contains the main nuclear reactions used for light element isotope determination. Two specificities of nuclear reactions must be outlined: the occurrence of nuclear resonances with strong increase of the reaction cross-section and the analytical interest offered by heavy ion induced nuclear reactions (Tab. V).

In the case of a non resonant nuclear reaction, the reaction yield is simply expressed by:

$$
Y=N_{0} \varepsilon \Delta \Omega n_{\mathrm{i}} \int_{\mathrm{E}_{0}}^{0} \sigma(E) \mathrm{d} E \int_{0}^{x}(1 / S(E)) \mathrm{d} x .
$$


Table IV. - Nuclear reactions leading to the emission of charged particles used for light element isotope analysis [6, 7, 9].

\begin{tabular}{|c|c|r|r|}
\hline Isotope & Reaction & Energy range & Reaction product* \\
\hline${ }^{2} \mathrm{H}$ & $(\mathrm{d}, \mathrm{p})$ & $0.3-1 \mathrm{MeV}$ & $p, 2-2.5 \mathrm{MeV}$ \\
\hline${ }^{3} \mathrm{H}$ & $(\mathrm{d}, \mathrm{n}) \alpha$ & $0.1-0.6 \mathrm{MeV}$ & $\alpha, 0.5-2.5 \mathrm{MeV}$ \\
\hline${ }^{3} \mathrm{He}$ & $(\mathrm{d}, \mathrm{p})$ & $0.3-2 \mathrm{MeV}$ & $p, 13-15 \mathrm{MeV}$ \\
\hline${ }^{6} \mathrm{Li}$ & $(\mathrm{d}, \alpha)$ & $1-2 \mathrm{MeV}$ & $\alpha, 9-10 \mathrm{MeV}$ \\
\hline${ }^{7} \mathrm{Li}$ & $(p, \alpha)$ & $1-4 \mathrm{MeV}$ & $\alpha, 7-10 \mathrm{MeV}$ \\
\hline${ }^{11} \mathrm{~B}$ & $(p, \alpha)$ & $0.6-0.7 \mathrm{MeV}$ & $\alpha, 3-3.5 \mathrm{MeV}$ \\
\hline${ }^{12} \mathrm{C}$ & $(\mathrm{d}, \mathrm{p})$ & $0.9-2.2 \mathrm{MeV}$ & $p, 3-3.5 \mathrm{MeV}$ \\
& $\left({ }^{3} \mathrm{He}, p\right)$ & $2-3 \mathrm{MeV}$ & $p, 6-7 \mathrm{MeV}$ \\
\hline${ }^{14} \mathrm{~N}$ & $(\alpha, p)$ & $3.7-4 \mathrm{MeV}$ & $p, 1-1.2 \mathrm{MeV}$ \\
\hline${ }^{16} \mathrm{O}$ & $(\mathrm{d}, \mathrm{p})$ & $0.8-2.2 \mathrm{MeV}$ & $p, 1-2.5 \mathrm{MeV}$ \\
\hline${ }^{18} \mathrm{O}$ & $(p, \alpha)$ & $0.6-2 \mathrm{MeV}$ & $\alpha, 3-3.5 \mathrm{MeV}$ \\
\hline${ }^{23} \mathrm{Na}$ & $(p, \alpha)$ & $0.5-1 \mathrm{MeV}$ & $\alpha, 2-2.5 \mathrm{MeV}$ \\
\hline${ }^{31} \mathrm{P}$ & $(p, \alpha)$ & $1.5-2 \mathrm{MeV}$ & $\alpha, 2.5-3.5 \mathrm{MeV}$ \\
\hline
\end{tabular}

${ }^{*}$ For a detection angle between 135 and $170^{\circ}$ and without absorber in front of the detector.

Table V. - Nuclear resonances in NRA and heavy ion induced reactions [6, 7, 9].

\begin{tabular}{|c|c|c|c|}
\hline Reaction & $\begin{array}{c}\text { Resonance energy } \\
(\mathrm{MeV})\end{array}$ & $\begin{array}{c}\text { Resonance width } \\
(\mathrm{keV})\end{array}$ & $\begin{array}{c}\text { Cross-section } \\
(\mathrm{mb})\end{array}$ \\
\hline${ }^{1} \mathrm{H}\left({ }^{15} \mathrm{~N}, \alpha \gamma\right){ }^{12} \mathrm{C}$ & 6.385 & 1.8 & 1650 \\
\hline${ }^{18} \mathrm{O}(\mathrm{p}, \alpha){ }^{15} \mathrm{~N}$ & 0.630 & 2.1 & 66 \\
\hline${ }^{23} \mathrm{Na}(\mathrm{p}, \alpha){ }^{20} \mathrm{Ne}$ & 0.592 & 0.6 & 200 \\
\hline${ }^{23} \mathrm{Na}(\mathrm{p}, \alpha \gamma){ }^{20} \mathrm{Ne}$ & 1.012 & 1.5 & \\
\hline${ }^{27} \mathrm{Al}(\mathrm{p}, \gamma){ }^{27} \mathrm{Al}$ & 0.992 & 0.1 & \\
\hline${ }^{31} \mathrm{P}(\mathrm{p}, \alpha){ }^{28} \mathrm{Si}$ & 1.892 & 23 & \\
\hline${ }^{48} \mathrm{Ti}(\mathrm{p}, \gamma){ }^{49} \mathrm{~V}$ & 1.361 & 0.05 & \\
\hline
\end{tabular}

An unknown sample is generally compared to a standard material irradiated in the same conditions and a common relationship can be derived from (10):

$$
n_{\mathrm{i}}=\left(n_{\mathrm{i}}\right)_{\text {std }} Y S_{\text {std }} / S Y_{\text {std }}
$$

with $Y$ and $Y_{\text {std }}$ the respective yield detected for the sample and a standard sample and $n_{\mathrm{i}}$ and $\left(n_{\mathrm{i}}\right)_{\text {std }}$ the respective concentration of atom $i$.

NRA is well adapted to the investigation of depth distribution of light element isotopes $(Z=1$ to $Z=30$ ) in the near surface region of solids [12].

2.4 COMPARISON OF METHODS. - Table VI gives the analytical performances allowed with nuclear analytical techniques. Figure 5 gives examples of typical spectra obtained on a glass ( 70 at. $\%$ 
Table VI. - Comparison of the analytical performances allowed by nuclear microprobe methods.

\begin{tabular}{|c|c|c|c|c|}
\hline Method & $\begin{array}{c}\text { Analyzed } \\
\text { elements }\end{array}$ & $\begin{array}{c}\text { Probing depth } \\
(\mu \mathrm{m})\end{array}$ & $\begin{array}{c}\text { Depth resolution } \\
(\mathrm{nm})\end{array}$ & $\begin{array}{c}\text { Sensitivity } \\
(\text { wt. Ppm) }\end{array}$ \\
\hline PIXE & from Na to U & $0.1-20$ & $500-10^{3}$ & $5-100$ \\
\hline PIGE & $\begin{array}{c}\text { from Li to } \mathrm{Zn} \\
\text { (isotopes) }\end{array}$ & $10-50$ & $500-10^{3}$ & $100-10^{3}$ \\
\hline RBS & & $0.001-10$ & $15-30$ & $100-10^{3}$ \\
\hline ERDA & H isotopes & $0.1-10$ & $20-40$ & $10-100$ \\
\hline PHESA & from Be to Si & $0.01-0.1$ & 1 & $10^{3}-10^{4}$ \\
\hline NRA & $\begin{array}{c}\text { from H to S } \\
\text { (isotopes) }\end{array}$ & $0.1-10$ & $5-500$ & $1-10^{3}$ \\
\hline
\end{tabular}

$\mathrm{SiO}_{2}, 10$ at. $\% \mathrm{Na}_{2} \mathrm{O}, 10$ at. $\% \mathrm{CaO}, 5$ at. $\% \mathrm{SnO}_{2}$ and 5 at. $\% \mathrm{PbO}$ ) with a $20 \mathrm{~nm}$ carbon surface coating to ensure charge flowing.

$\mathrm{X}$-ray and gamma-ray spectra in Figures $5 \mathrm{a}$ and $5 \mathrm{~b}$ are typical line spectra in which the peak energy gives the nature of the element and the peak area is proportional to the concentration. Scattering spectra in Figures 5c and 5d are composed of successive continuous steps ranged in increasing mass order corresponding to thick elemental distributions $(\mathrm{O}, \mathrm{Na}, \mathrm{Si}, \mathrm{Ca}, \mathrm{Sn}$ and $\mathrm{Pb}$ ) and/or narrow peaks corresponding to thin elemental distributions (for example C). The ERDA spectrum of Figure 5e can be divided in two parts: a surface $\mathrm{H}$ peak and a continuous bulk distribution, this data indicates the superficial hydration of the glass sample. The NRA spectrum of Figure $5 \mathrm{f}$ is composed of several energy zones, each corresponding to a specific nuclear reaction: $(d, p)$ reactions on ${ }^{16} \mathrm{O}$ and ${ }^{12} \mathrm{C}$ in our case. The shape of the zone is the image of the depth distribution of the analysed element. The narrow carbon peak corresponds to the nuclear reaction events occuring within the surface coating.

The quantitative interpretation of such spectra is generally based on "simulation-iteration" computer programs including a complete description of all the basic physical processes involved. It also requires the knowledge of the target contents for major elements for a correct modelling of energy loss and attenuation effects [11, 13-17].

Table VII tries to compare the analytical capabilities of nuclear microprobe analysis combining these six methods with those from other current microanalytical techniques used for bulk solid characterization or surface analysis, such as Electron Microprobe Analysis, Micro X-ray Photoelectron Spectroscopy, Auger Microprobe, Secondary Ion Microprobe and Laser Microprobe Mass Analysis.

The main characteristic of nuclear microanalysis lies in its ability to quantitatively determine the isotopes of light elements from ${ }^{1} \mathrm{H}$ up to ${ }^{19} \mathrm{~F}$. Nevertheless, depth resolution and detection limits are not as good as for ion probe. Scattering techniques (RBS, PHESA and ERDA) are essentially devoted to surface analysis while PIXE, PIGE and NRA are efficient for bulk analysis. One of the major limitation in the use of nuclear microanalysis lies on the irradiation sensitivity of the target material.

\section{Applications of Nuclear Microanalysis}

A lot of application examples of nuclear microanalysis in materials sciences, earth sciences and life sciences have been published since the beginning of the seventies and particularly in the proceedings of the four first nuclear microprobe conferences [18-21]. In the following sections, we will try to briefly illustrate the analytical capabilities of nuclear microanalysis in different fields 


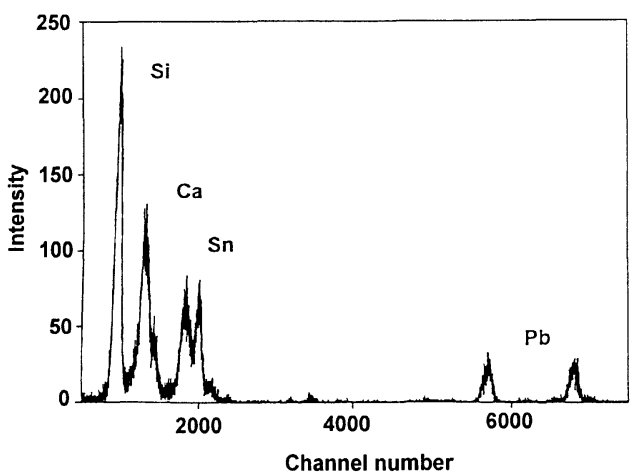

a)

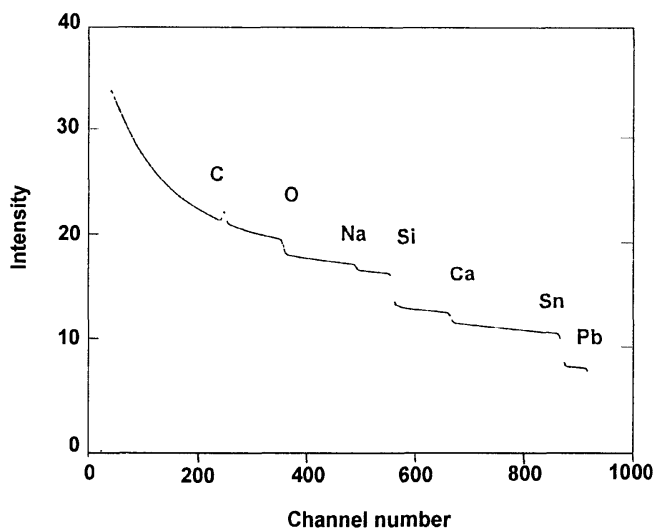

c)

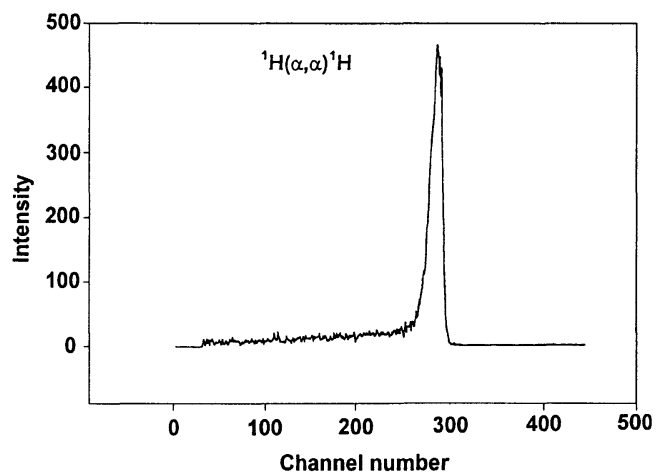

e)

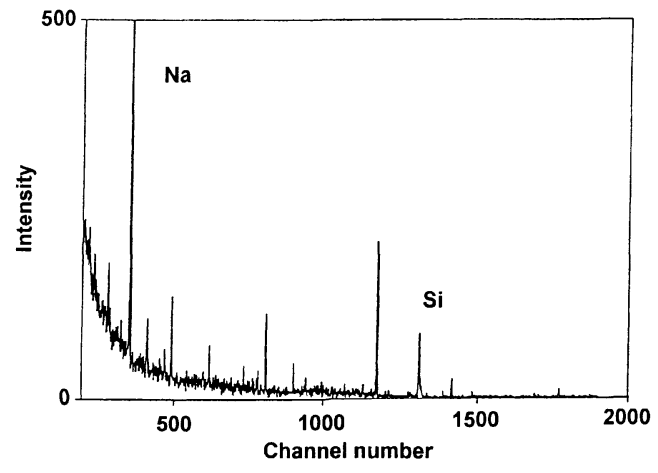

b)

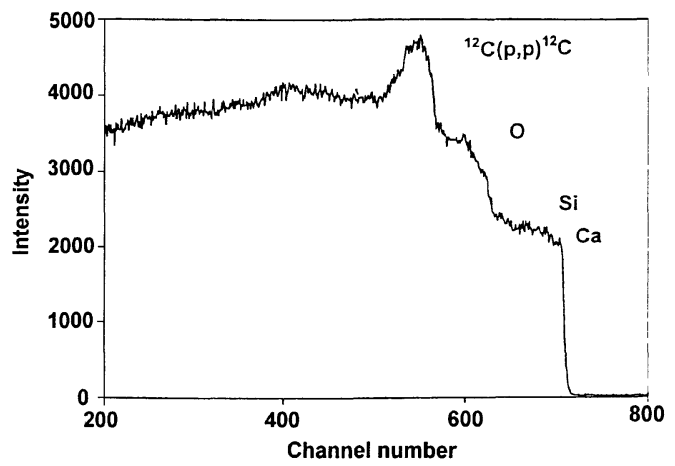

d)

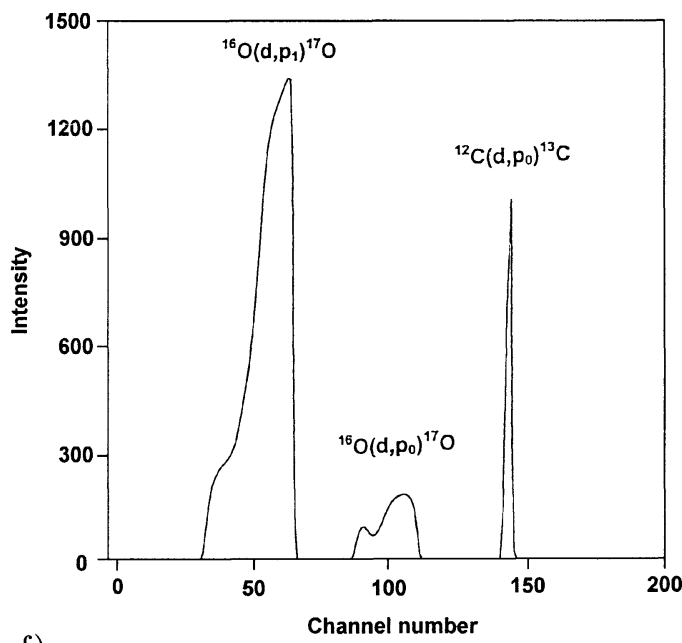

f)

Fig. 5. - Typical nuclear microanalysis spectra obtained by irradiating a glass sample under appropriate conditions: a) PIXE data; b) PIGE data; c) PESA data (1.725 MeV proton beam, $10 \times 10 \mu \mathrm{m}^{2}, 100 \mathrm{pA}$, $0.1 \mu \mathrm{C})$; d) RBS data; e) ERDA data $\left(3 \mathrm{MeV}^{4} \mathrm{He}^{+}\right.$beam, $\left.10 \times 10 \mu \mathrm{m}^{2}, 100 \mathrm{pA}, 0.5 \mu \mathrm{C}\right)$; f) NRA data ( $0.9 \mathrm{MeV}$ deuteron beam, $10 \times 10 \mu \mathrm{m}^{2}, 200 \mathrm{pA}, 0.5 \mu \mathrm{C}, 12 \mu \mathrm{m} \mathrm{Al}$ absorber in front of the detector). 
Table VII. - Comparison of the analytical capabilities offered by various microanalytical techniques.

\begin{tabular}{|c|c|c|c|c|}
\hline Technique & $\begin{array}{c}\text { Spatial } \\
\text { resolution }\end{array}$ & $\begin{array}{c}\text { Detection limit } \\
(\text { at. } \%)\end{array}$ & Information & Damage \\
\hline $\begin{array}{c}\text { Electron } \\
\text { microprobe }\end{array}$ & $0.5 \mu \mathrm{m}$ & $10^{-3}-10^{-1}$ & local, 2D & $\begin{array}{l}\text { migration of } \\
\text { volatile } \\
\text { elements }\end{array}$ \\
\hline $\begin{array}{c}\text { XPS } \\
\text { microprobe }\end{array}$ & $2 \mu \mathrm{m}$ & $>1$ & local, 2D, 3D & surface erosion \\
\hline $\begin{array}{c}\text { Auger } \\
\text { microprobe }\end{array}$ & $20 \mathrm{~nm}$ & $>0.1$ & local,2D, 3D & surface erosion \\
\hline lon probe & $0.2 \mu \mathrm{m}$ & $10^{-7}-10^{-3}$ & $\begin{array}{l}\text { local, 2D, 3D } \\
\text { isotopes }\end{array}$ & surface erosion \\
\hline Laser probe & $0.5 \mu \mathrm{m}$ & $10^{-5}-10^{-2}$ & $\begin{array}{l}\text { local, 2D, 3D } \\
\text { isotopes }\end{array}$ & surface erosion \\
\hline $\begin{array}{l}\text { Synchrotron } \\
\text { X-ray probe }\end{array}$ & $1 \mu \mathrm{m}$ & $10^{-5}-10^{-3}$ & local, 2D & \\
\hline $\begin{array}{c}\text { Nuclear } \\
\text { microprobe }\end{array}$ & $1 \mu \mathrm{m}$ & $10^{-4}-10^{-2}$ & $\begin{array}{l}\text { local, 2D, 3D } \\
\text { isotopes }\end{array}$ & $\begin{array}{c}\text { thermal electric } \\
\text { ballistic }\end{array}$ \\
\hline
\end{tabular}

using when they will be available data obtained with the nuclear microprobe facility of Laboratoire Pierre Süe.

3.1 Materials Sciences. - Nuclear microprobe applications in materials sciences deal with the characterization of thin films and multilayered solids and the study of elemental transport mechanisms through interfaces as well for metallurgical and microelectronics purposes as for new materials or in nuclear technology (see Sects. IX and X in [21]).

For example, Cachoir and coworkers studied the alteration mechanisms of bulk uranium dioxide by a granitic groundwater in order to determine the nature of secondary phases able to control its solubility. Under oxic conditions they have found that $\mathrm{UO}_{2}$ solubility is governed by the crystallisation of U(VI) hydrate: schoepite. A micro-PHESA spectrum is given in Figure 6 showing the splitting of both uranium and oxygen steps corresponding to the presence of a few $\mu \mathrm{m}$ partially dehydrated $\mathrm{UO}_{2}(\mathrm{OH})_{2}$ crystal onto the $\mathrm{UO}_{2}$ surface [22].

3.2 Earth And Planetary Sciences. - Earth sciences applications of nuclear microprobe include trace element geochemistry, earth structure and geological processes studies (see Sect. VIII in [21]). Cosmochemistry has been also considered for a long time as a potential application field for nuclear microprobe analysis, essentially through meteorites characterization [23].

Strong efforts are now devoted to the study of platinum-group minerals in order to understand their formation mechanisms. Criddle and co-workers combined electron probe microanalysis and microPIXE to investigate the distributions of platinum-group elements in samples from the collection of the Natural History Museum in London [24]. Figure 7 gives an example of the data they obtained on a compound grain of Pt-Fe alloy and osmium bearing ruthenium from the Esterly mine, Oregon, USA. Darker regions in the maps indicate higher concentrations of the elements. The Pt-richest regions rarely exceed $20 \mathrm{wt}$. ppm. Elemental mapping demonstrates the extreme inhomogeneity of the grain with platinum-rich zones within its ruthenium-osmium host alternating with platinum-poor zones. The authors found that microPIXE seems to be more useful than 


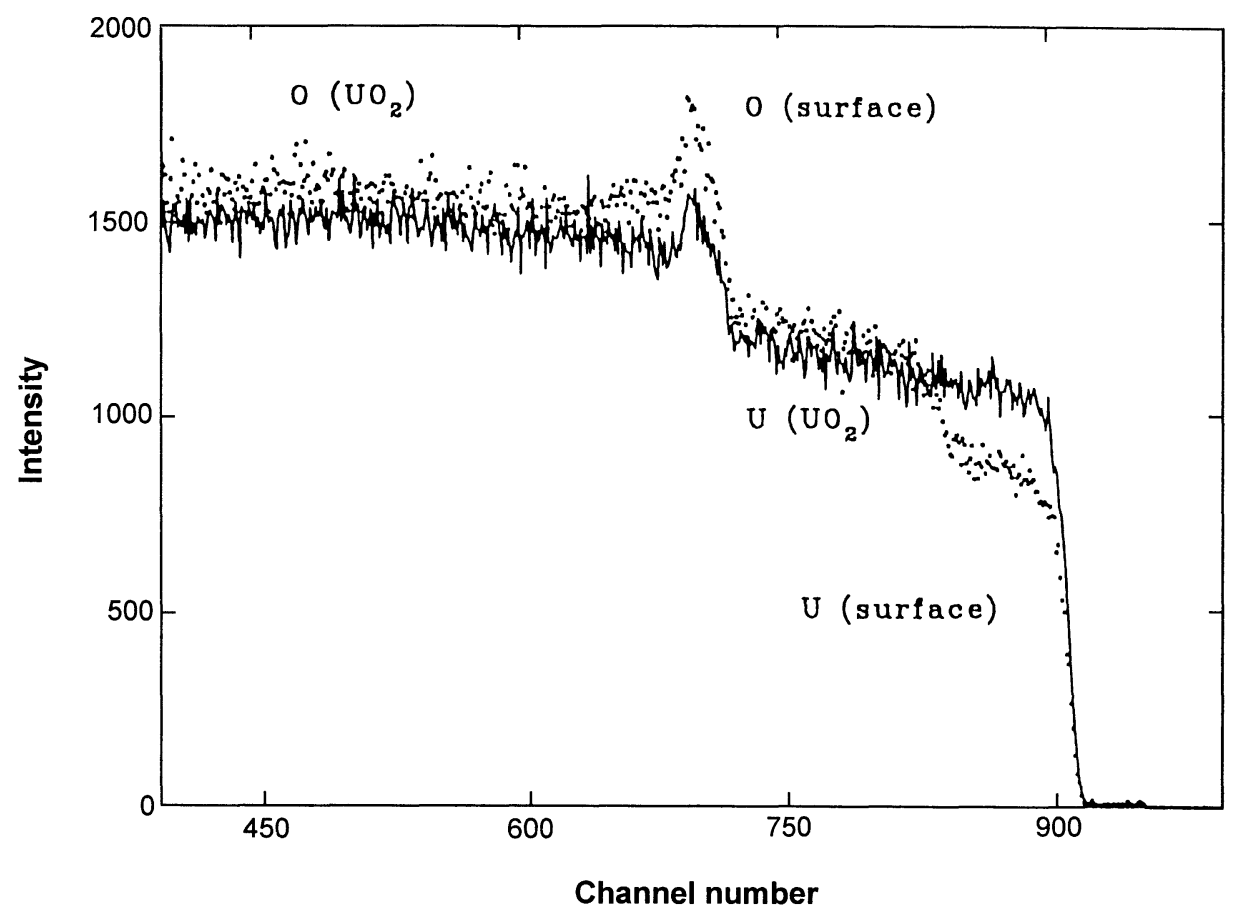

Fig. 6. - Comparison of experimental spectra for a schoepite crystal onto the surface of a leached $\mathrm{UO}_{2}$ sample and a reference $\mathrm{UO}_{2}$ sample (unleached): protons $3.47 \mathrm{MeV}$, beam spot $=10 \times 10 \mu \mathrm{m}^{2}$, current $=100 \mathrm{pA}$, dotted line $=$ schoepite spectrum, full line $=$ reference spectrum (data from [22]).

EIXE as an exploratory tool in rapid analysis of such complex materials, essentially due to the better detection limits available.

3.3 LifE SCIENCES. - The use of $1 \mu \mathrm{m}^{2}$ proton microbeam in life sciences gives rise to relevant applications in the field of cell biology or medicine (see Sect. VII in [21]).

For example, in a recent review Watt and Landsberg reported data concerning the control for patients suspected of heavy metal poisoning [25]. Hair strand cross section were mapped using microPIXE (Fig. 8). Hair was taken from a patient known to have clinical symptoms corresponding to lead poisoning. $\mathrm{Ca}, \mathrm{Cu}, \mathrm{K}, \mathrm{Si}$ and $\mathrm{Fe}$ are identified with contamination caused by external sources, relatively to internal constituents of hair with uniform distributions as $\mathrm{S}$ and $\mathrm{P}$. The contamination level goes from a few wt. $\mathrm{ppm}$ for $\mathrm{Pb}$ to hundred of $\mathrm{ppm}$ for $\mathrm{Ca}$ and $\mathrm{Si}$. The contamination process is not homogeneous because poisoned hair is enriched in $\mathrm{Fe}, \mathrm{Si}$ and $\mathrm{Ca}$ around its perimeter while $\mathrm{Cu}$ contamination is quasi uniform inside the hair. $\mathrm{Pb}$ has a typical distribution which is low in the centre of the hair and increases slowly towards the perimeter. This perhaps reflects the metabolic mechanism in which heavy metals are sequestered in the hair by means of a transcellular route through the root sheath. In the poisoned hair, the average content of lead is $13 \mathrm{wt}$. ppm and in a normal hair it is not higher than $3 \mathrm{ppm}$.

3.4 Human Sciences. - Archaeometry and arts also constitute a typical application field of nuclear microprobe, located at the crossing between materials and life sciences (see Sect. XI in [21]).

Barré and Trocellier have recently demonstrated that the combination of microPIXE using a $3 \mathrm{MeV}$ proton microbeam and microNRA using a $1.8 \mathrm{MeV}$ deuteron microbeam allows 
the distributions of the main constituents of ancient bone tissues to be measured. In the case of a transverse section of a femur issued from a woman skeleton from a French necropolis near Lyon (fourth to sixth century), $\mathrm{Ca}, \mathrm{O}, \mathrm{C}$ and $\mathrm{Pb}$ profiles are given in Figure 9 [26]. This skeleton was burried in a lead sarcophagus and nuclear microanalysis data show that lead was strongly incorporated in the calcium phosphate matrix, leading to a decrease of the alteration of the bone tissue in terms of both alkali ions and organic fraction losses due to the precipitation of mixed $\mathrm{Pb}$ and $\mathrm{Ca}$ phosphate and carbonate.

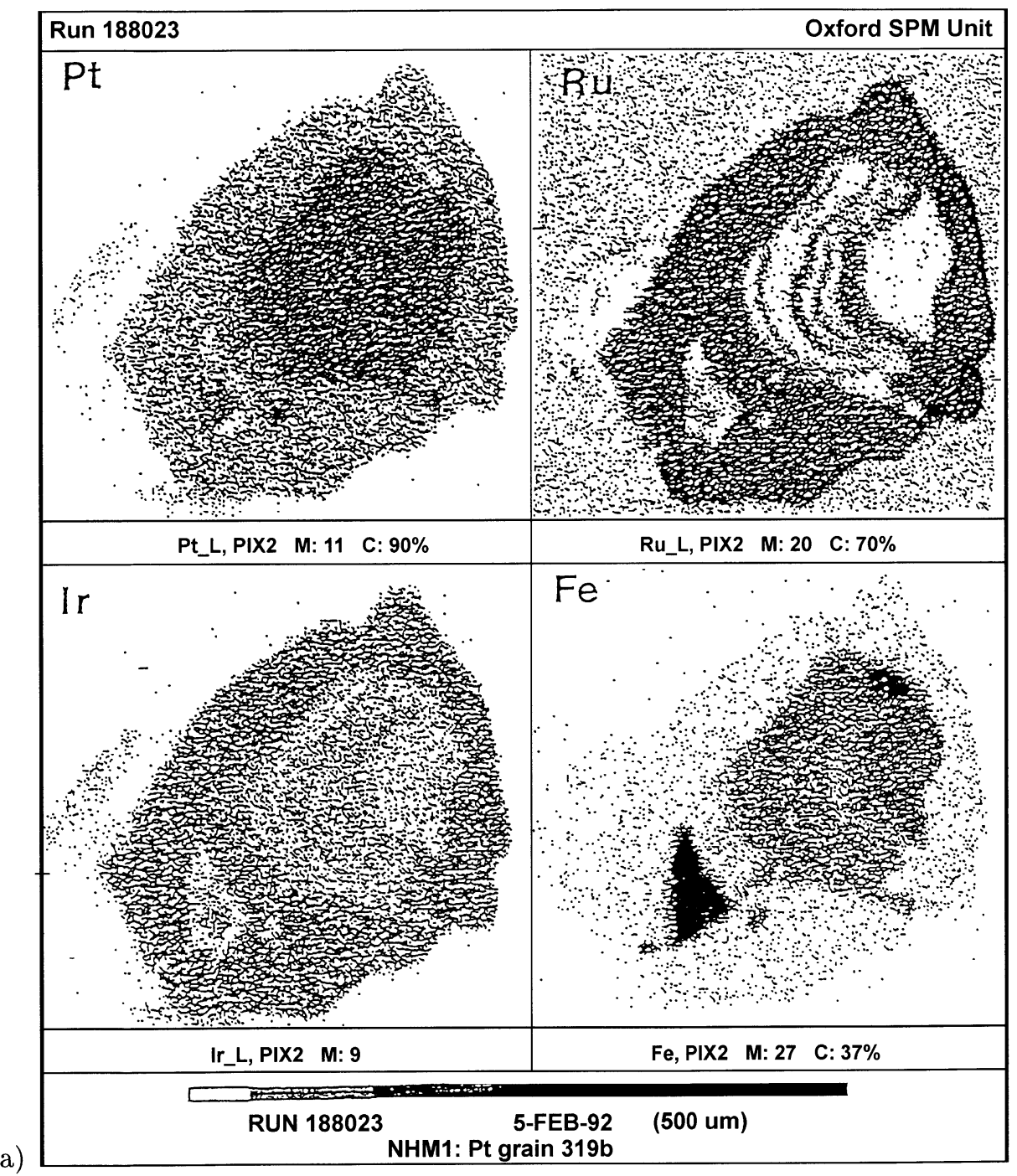

Fig. 7. - a) MicroPIXE elemental maps of a Pt grain (3 MeV proton microbeam, diameter of $1 \mu \mathrm{m}$, $250 \mathrm{pA}$ ). Maps of $\mathrm{Pt}, \mathrm{Ru}, \mathrm{Ir}$ and $\mathrm{Fe}$ are presented, the area of each map is $500 \mu \mathrm{m}$ and darker regions indicate higher concentrations of the elements; b) and c) linear distributions along the horizontal centre line of Figure 5a. The data is presented as raw counts per channel and is not background-corrected (data from [24]). 

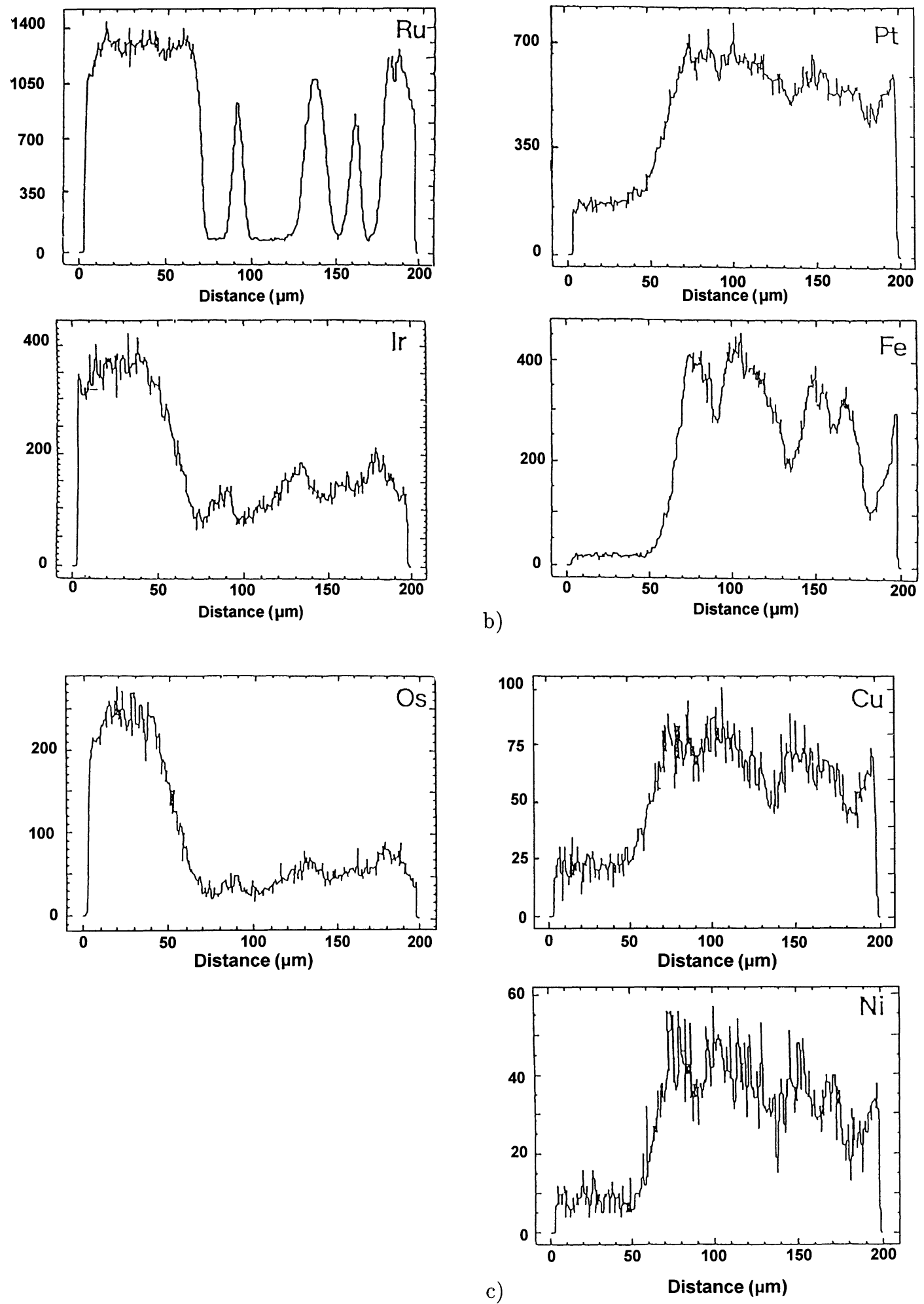

Fig. 7. - (Continued) 


\section{Recent Developments and Further Progresses}

4.1 Analytical Methods. - Since the beginning of the nineties, reliable progresses in nuclear microprobe analysis deal with the development of new imaging techniques. First of all, scanning transmission ion microscopy (STIM) is based on the transmission of incident ions (3-4 MeV protons for example) through thin targets $(0.1-10 \mu \mathrm{m})$ with a very low beam current density $\left(10^{-15} \mathrm{~A}\right.$ in $50 \mathrm{~nm}$ diameter probe) [27]. 3D elemental distributions can be obtained using energy loss or $\mathrm{X}$-ray spectroscopies.

Ion microtomography (IMT) constitutes the extension of STIM combined with a spatial rotation of the sample under investigation [28]. Ionoluminescence (IL) is based on the detection of light photon emission induced by the incident ion bombardment [29].

$2 \mathrm{D}$ images and data on the electronic configuration of excited atoms can be obtained. Ion beam induced current (IBIC) is similar to EBIC technique that is largely used to study semiconductor materials [30].

Channeling techniques have been extensively developed for studying defects in monocrystalline and polycrystalline solids [31]. Single ion techniques seem to offer interesting opportunities to study the behaviour of basic functional units of microelectronic circuits under irradiation or the radiation sensitivity of the constituents of biological cells [32].

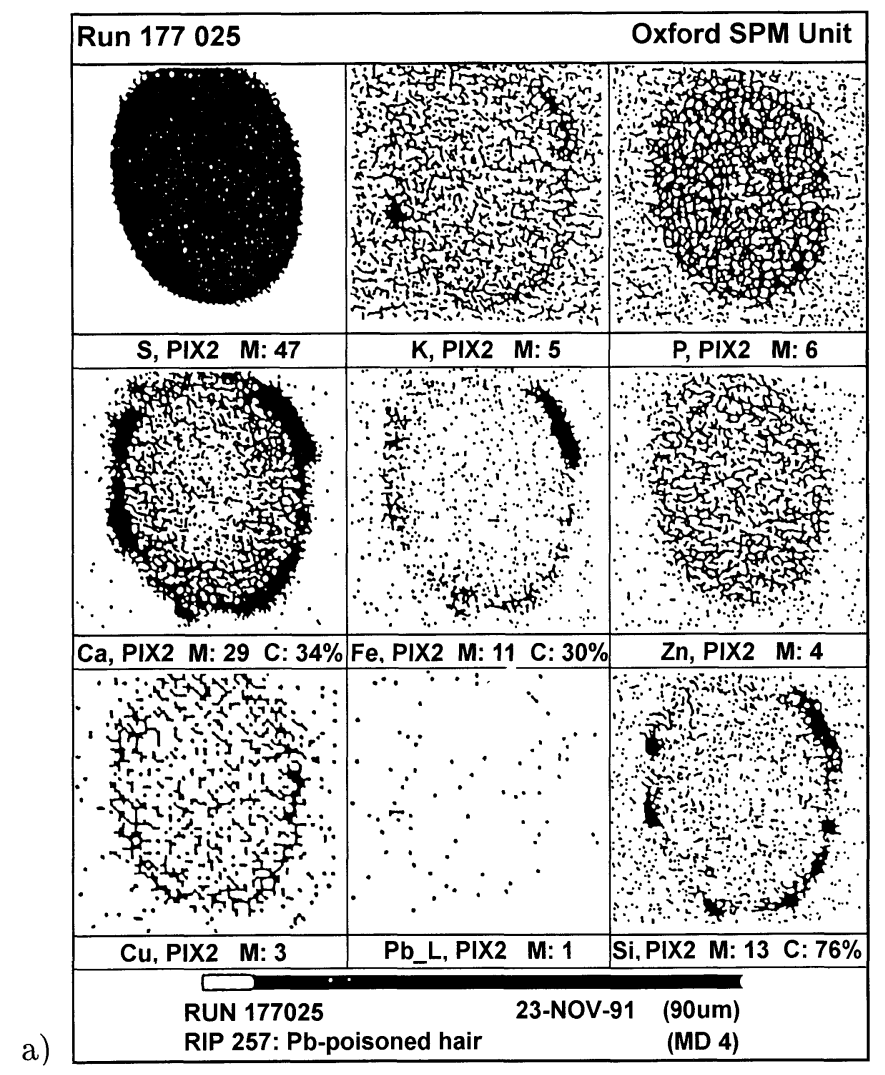

Fig. 8. - a) PIXE maps $\left(90 \times 90 \mu \mathrm{m}^{2}\right)$ of a cross section of a hair strand from a patient diagnosed as suffering from lead poisoning obtained with a $0.5 \mu$ m diameter $3 \mathrm{MeV}$ proton microbeam $(100 \mathrm{pA})$ : top row $\mathrm{S}, \mathrm{K}$ and $\mathrm{P}$, middle row $\mathrm{Ca}, \mathrm{Fe}$ and $\mathrm{Zn}$, bottom row $\mathrm{Cu}, \mathrm{Pb}$ and $\mathrm{Si}$; b) PIXE line scans across the same section of a hair strand (data from [25]). 

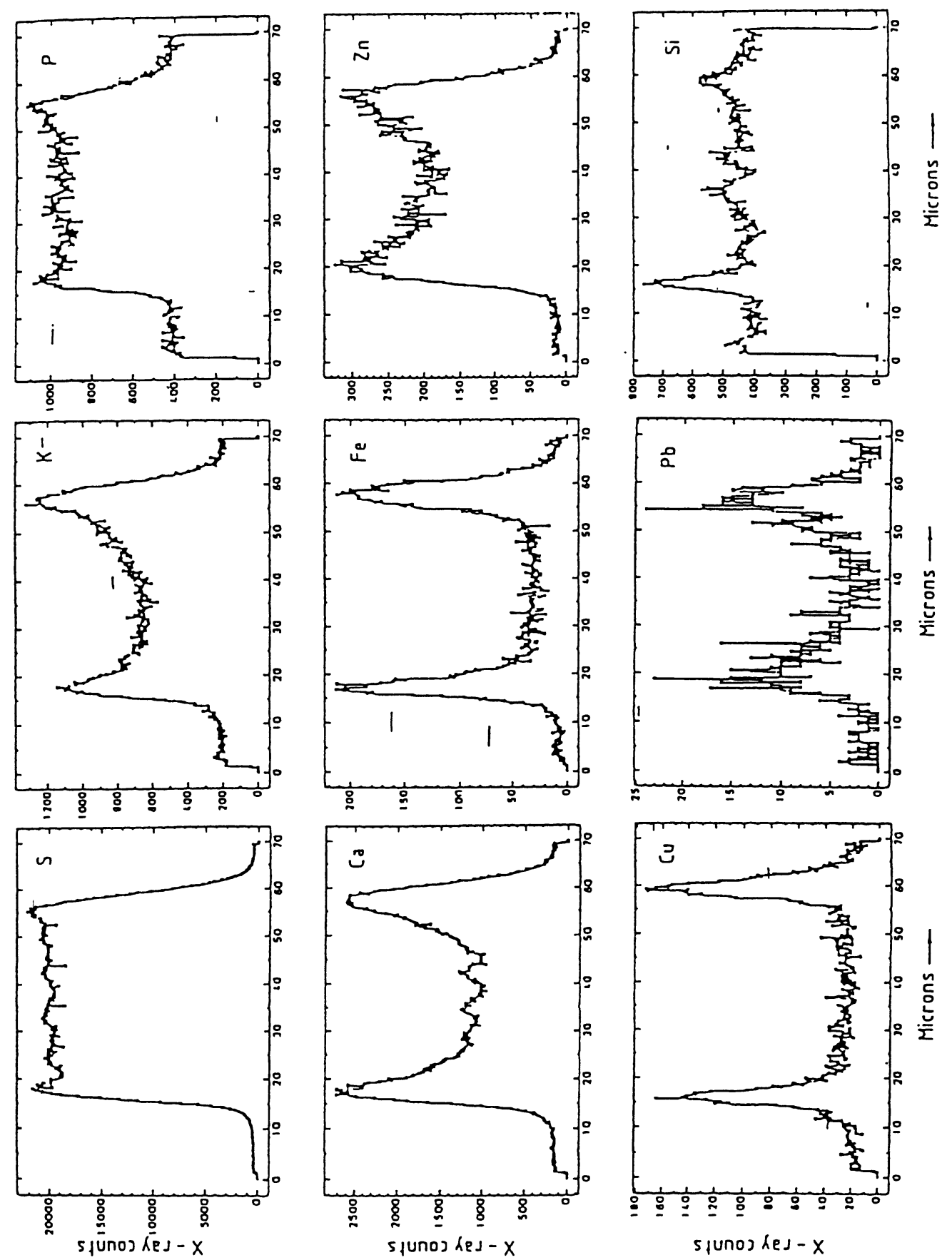

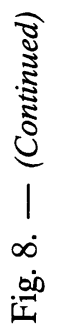



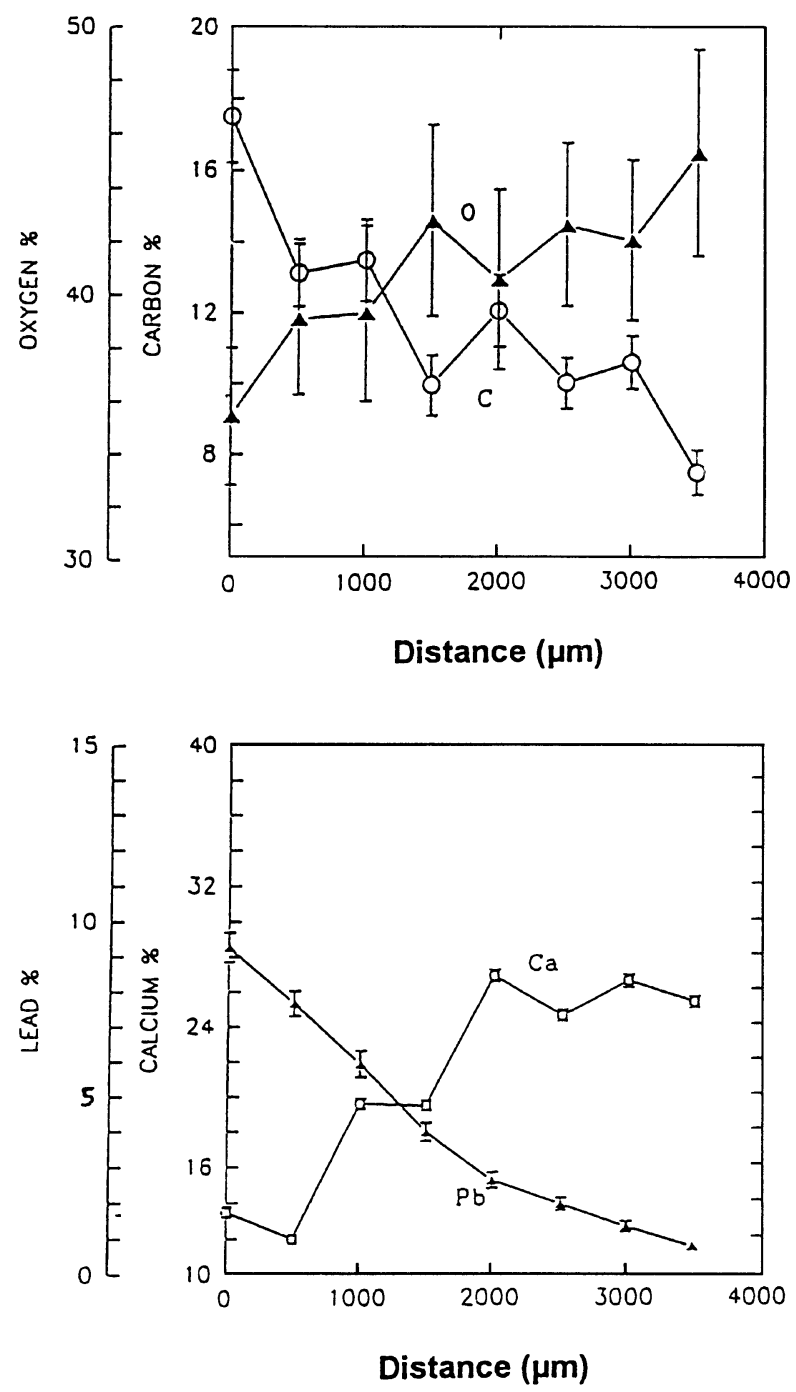

Fig. 9. - Carbon, oxygen, calcium and lead distributions in a transverse femur section issued from a woman skeleton from a french necropolis near Lyon determined by microPIXE and microNRA ( $3 \mathrm{MeV}$ proton microbeam and $1.8 \mathrm{MeV}$ deuteron microbeam, $1.2 \mathrm{nA}$, beam size $=15 \mu \mathrm{m} \times 15 \mu \mathrm{m}, 300 \mathrm{~s} / \mathrm{pixel}$ ). The concentration scales are expressed in wt.\% (data from [26]).

4.2 Beam Technology. - Ion optics and ion sources benefit from valuable developments in order to improve the spatial resolution $(0.1 \mu \mathrm{m})$ and to increase the probe brightness [33]. Strong efforts are devoted to the limitation of parasitic aberrations for focusing lenses (see Sect. II in [21]). The use of high energy heavy ions focused beams appears as a very promising research axis [11].

4.3 Data Processing and Detection Devices. - Recent progress also concerns the development of computing codes for data handling and probe control (see Sect. III in [21]). Moreover, the use of several new detection devices as for example solid state telescope constituted by a thin detector $(\Delta E)$ and a thick detector $\left(E_{\mathrm{r}}\right)$, electromagnetic filter, gas ionization chamber, electrostatic and magnetic crossed fields spectrometer, time of flight spectrometer and the development 
of coincidence spectroscopy strongly improve the mass separation power and the sensitivity of ion microbeam techniques [11].

4.4 Application Topics. - Application of nuclear microanalysis techniques in the field of environmental sciences knows a growing interest [34]. Last but not least, nuclear microprobe starts to be also used for more fundamental studies on ion beam interactions with condensed matter. For example, Boutard and coworkers have demonstrated the influence of the microbeam current density on elemental loss for thin copper or gold coated on silicon [35]. Berger and coworkers have measured the temperature gradient induced by a microbeam irradiation in the near surface region of a glass [36]. Mosbah and coworkers have determined the $3 \mathrm{D}$ distributions of $\mathrm{Na}$ and $\mathrm{Ca}$ in ternary glasses around the microbeam impact [37].

\section{Conclusion}

With this overview on nuclear microprobe analytical methods, application examples and recent developments, it can clearly be concluded that the quantitative elementary analysis and imaging capabilities of the nuclear microprobe have continuously been strengthened over the past ten years, raising nuclear microanalysis to a very competitive level with other microanalytical methods.

\section{Acknowledgements}

This paper is based on an invited talk given at the Eleventh Conference of the European Societies for Electron Microscopy (EUREM'96) in Dublin (Ireland), 26-30 August 1996. I wish to thank the Organizing Committee of EUREM'96 for his invitation and his financial support.

Moreover, I want to sincerely acknowledge an anonymous referee for his very stimulating critical review of the initial version of this paper.

\section{References}

[1] Cookson J.A., Ferguson A.T.G. and Pilling F.D., J. Radioanal. Chem. 12 (1972) 39.

[2] Grime G.W. and Watt F., Beam optics of quadrupole probe-forming systems (Adam Hilger, Bristol, 1984).

[3] Vis R.D., The proton microprobe: Applications in the biomedical field (CRC Press, Boca Raton, 1985).

[4] Revel G. and Duraud J.P., Techniques de l'Ingénieur 10 P2563 (1985) 1.

[5] Johansson S.A.E. and Campbell J.L., PIXE: A Novel Technique for Elemental Analysis (John Wiley and Sons Ltd, Chichester, 1988).

[6] Mayer J.W. and Rimini E., Ion Beam Handbook for Material Analysis (Academic Press, New York, 1977).

[7] Bird J.R. and Williams J.S., Ion Beam Handbook for Materials Analysis (Academic Press, Sydney, 1990).

[8] Chu W.K., Mayer J.W. and Nicolet M.A., Backscattering Spectrometry (Academic Press, New York, 1978).

[9] Tessmer J.R. and Nastasi M., Handbook of Modern Ion Beam Materials Analysis (Materials Research Society, Pittsburgh, 1995).

[10] Mercier F., Toulhoat N., Trocellier P. and Durand C., Nucl. Instrum. and Methods in Phys. Res. $\mathbf{B 8 5}$ (1994) 874.

[11] Tirira J., Serruys Y. and Trocellier P., Forward Recoil Spectrometry: Applications to Hydrogen Determination in Solids (Plenum Press, New York, 1996).

[12] Deconninck G., Introduction to Radioanalytical Physics (Elsevier Scientific Publishing Company, Amsterdam, 1978). 
[13] Trouslard P., CEA Report R-5703 (1995).

[14] Doolittle L.R., Nucl. Instrum. and Methods in Phys. Res. B9 (1985) 344, B15 (1986) 227.

[15] Tirira J., Bodart F., Serruys Y. and Morciaux Y., Nucl. Instrum. and Methods in Phys. Res. B79 (1993) 565.

[16] Campbell J.L., Teesdale W.J. and Leigh R.G., Nucl. Instrum. and Methods in Phys. Res. B6 (1985) 551.

[17] Vizkelethy G., Nucl. Instrum. and Methods in Phys. Res. B45 (1990) 1.

[18] Proceedings of the First International Conference on Nuclear Microprobe Technology and Applications, Oxford, UK, 1-4 September 1987, Nucl. Instrum. and Methods in Phys. Res. B30 (1988), G. Grime and F.W. Watt Eds.

[19] Proceedings of the Second International Conference on Nuclear Microprobe Technology and Applications, Melbourne, Australia, 5-9 February 1990, Nucl. Instrum. and Methods in Phys. Res. B54 (1991), G.J.F. Legge and D.N. Jamieson Eds.

[20] Proceedings of the Third International Conference on Nuclear Microprobe Technology and Applications, Uppsala, Sweden, 8-12 June 1992, Nucl. Instrum. and Methods in Phys. Res. B77 (1993), U. Lindh Ed.

[21] Proceedings of the Fourth International Conference on Nuclear Microprobe Technology and Applications, Shanghai, China, 10-14 October 1994, Nucl. Instrum. and Methods in Phys. Res. B104 (1995), Fujia Yang, Jiayong Tang and Jieqing Zhu Eds.

[22] Cachoir C., Trocellier P., Guittet M.J. and Gallien J.P., Radiochimica Acta 74 (1996) 59.

[23] Vis R.D., Kik A.C. and Kramer J.L.A.M., Nucl. Instrum. and Methods in Phys. Res. B104 (1995) 395.

[24] Criddle A.J., Tamana H., Spratt J., Reeson K.J., Vaughan D. and Grime G., Nucl. Instrum. and Methods in Phys. Res. B77 (1993) 444.

[25] Watt F. and Landsberg J.P., Nucl. Instrum. and Methods in Phys. Res. B77 (1993) 249.

[26] Barré-Boscher N. and Trocellier P., Nucl. Instrum. and Methods in Phys. Res. B73 (1993) 413.

[27] Bench G., Saint A., Legge G.J.F. and Cholewa M., Nucl. Instrum. and Methods in Phys. Res. B77 (1993) 175.

[28] Schofield R.M.S., Nucl. Instrum. and Methods in Phys. Res. B104 (1995) 212.

[29] Yang C., Larsson N.P.-O., Swietlicki E. and Malmqvist K.G., Nucl. Instrum. and Methods in Phys. Res. B77 (1993) 188.

[30] Breese M.B.H., Grime G.W. and Watt F., Nucl. Instrum. and Methods in Phys. Res. B77 (1993) 243.

[31] King P.J.C., Breese M.B.H., Wilshaw P.R. and Grime G.W., Nucl. Instrum. and Meth. In Phys. Res. B104 (1995) 233.

[32] Fischer B.E. and Metzger S., Nucl. Instrum. and Methods in Phys. Res. B104 (1995) 7.

[33] Martin F.W. and Goloskie R., Nucl. Instrum. and Methods in Phys. Res. 354 (1991) 64.

[34] Orlic I., Nucl. Instrum. and Methods in Phys. Res. B104 (1995) 602.

[35] Boutard D. and Berthier B., Nucl. Instrum. and Methods in Phys. Res. B106 (1996) 1106.

[36] Berger P., Plumereau G. and Ladieu F., Temperature measurements under microbeam irradiation, Communication to the Fifth International Conference on Nuclear Microprobe Technology and Applications, Santa Fe (New Mexico), 10-15 November 1996, chaired by B.L. Doyle (Sandia National Laboratories, Albuquerque).

[37] Mosbah M. and Duraud J.P., Proton microbeam induced damages in glasses: Ca and Na distribution modification, Communication to the Fifth International Conference on Nuclear Microprobe Technology and Applications, Santa Fe (New M.'exico), 10-15 November 1996, chaired by B.L. Doyle (Sandia National Laboratories, Albuquerque). 